\title{
A medley of flavours
}

As I write this editorial, the summer is in full bloom. On holiday in California, at stops on Highway 1, the articles for the August issue of The Journal of Laryngology \& Otology are set in order, and this is said to whet your appetite.

Quality of life and survival are the bedrock of cancer therapy. Morand et al. report on oropharyngeal cancer patients treated with primary chemoradiation. ${ }^{1}$ The authors show that salivary gland transfer helps to reduce xerostomia and improve quality of life. They discuss the delay that this transfer may cause and consider whether it is detrimental to oncological outcomes.

That a trainee collaborative research network has developed to the level of a survey involving 42 secondary care centres ${ }^{2}$ is to be welcomed. The survey shows the variation in practice in peritonsillar abscess management across the UK and the rate of adverse events at 30 days, and presents a case for the use of steroids and possible out-patient based management for milder cases. This network could provide a solid base for further collaborative audit and research. A previous paper investigating risk factors for recurrence of peritonsillar abscess adds to these findings. ${ }^{3}$

The contention that personal music systems used at high volume are harmful to hearing is corroborated by Kumar and Deepashree's experimental work involving 60 participants. ${ }^{4}$ The authors found that personal music systems used at high volumes led to: elevated high frequency thresholds, reduced frequency discrimination and temporal modulation detection, and poor speech perception. This puts in perspective university students' attitudes towards hearing loss caused by attendance at night clubs. ${ }^{5}$

Jervis and Skinner's paper on screening for arteriovenous malformation in hereditary haemorrhagic telangiectasia cases provides a useful update for the busy otolaryngologist. ${ }^{6}$ It evaluates the pros and cons of screening for congenital arteriovenous malformation, and considers the role of genetics. This adds to a previous paper on the subject, which cites the lack of a UK-wide guideline on the management of hereditary haemorrhagic telangiectasia. ${ }^{7}$
The stability of cochlear implant outcomes over time in elderly patients has been controversial. Neural plasticity and neurodegeneration have raised concerns about the benefits and costs of implanting. The paper by Hilly et al. on the subject is timely; in their patients, the outcomes were stable over six years. ${ }^{8}$

The irritating term 'seven-day working' for doctors has now become a part of political discourse. Patel et al. focus on current weekend work and consider whether weekend surgery is a risk factor in the management of post-operative haemorrhage. ${ }^{9}$ They show that it is not.

\section{MUSHEER HUSSAIN EDWARD FISHER ROBIN YOUNGS JONATHAN FISHMAN Senior Editors}

\section{References}

1 Morand GB, Madana J, da Silva SD, Roskies M, Sultanem K, Black MJ et al. Survival and quality of life in oropharyngeal cancer patients treated with primary chemoradiation after salivary gland transfer. J Laryngol Otol 2016;130:755-62

2 ENT Trainee Research Collaborative - West Midlands. National prospective cohort study of peritonsillar abscess management and outcomes: the Multicentre Audit of Quinsies (MAQ) study. J Laryngol Otol 2016;130:768-76

3 Chung JH, Lee YC, Shin SY, Eun YG. Risk factors for recurrence of peritonsillar abscess. J Laryngol Otol 2014;128:1084-8

4 Kumar UA, Deepashree SR. Personal music systems and hearing. J Laryngol Otol 2016;130:717-29

5 Johnson O, Andrew B, Walker D, Morgan S, Aldren A. British university students' attitudes towards noise-induced hearing loss caused by nightclub attendance. J Laryngol Otol 2014;128: 29-34

6 Jervis S, Skinner D. Screening for arteriovenous malformations in hereditary haemorrhagic telangiectasia. J Laryngol Otol 2016; 130:734-42

7 Syed I, Sunkaraneni VS. Evidence-based management of epistaxis in hereditary telangiectasia. J Laryngol Otol 2015;129: 410-15

8 Hilly O, Hwang E, Smith L, Shipp D, Nedzelski JM, Chen JM et al. Cochlear implantation in elderly patients: stability of outcome over time. J Laryngol Otol 2016;130:706-11

9 Patel A, Foden N, Rachmanidou A. Is weekend surgery a risk factor for post-tonsillectomy haemorrhage? J Laryngol Otol 2016;130:763-7 